\title{
Murine Embryonic Stem Cell-Derived Pyramidal Neurons Integrate into the Cerebral Cortex and Appropriately Project Axons to Subcortical Targets
}

\author{
Makoto Ideguchi, ${ }^{1}$ Theo D. Palmer, ${ }^{2}$ Lawrence D. Recht, ${ }^{1}$ and James M. Weimann ${ }^{1}$ \\ Departments of ${ }^{1}$ Neurology and ${ }^{2}$ Neurosurgery, Stanford Medical School, Stanford, California 94305
}

\begin{abstract}
Although embryonic stem (ES) cells have been induced to differentiate into diverse neuronal cell types, the production of cortical projection neurons with the correct morphology and axonal connectivity has not been demonstrated. Here, we show that in vitro patterning is critical for generating neural precursor cells (ES-NPCs) competent to form cortical pyramidal neurons. During the first week of neural induction, these ES-NPCs begin to express genes that are specific for forebrain progenitors; an additional week of differentiation produces mature neurons with many features of cortical pyramidal neurons. After transplantation into the murine cerebral cortex, these specified ES-NPCs manifest the correct dendritic and axonal connectivity for their areal location. ES-NPCs transplanted into the deep layers of the motor cortex differentiate into layer 5 pyramidal neurons and extend axons to distant subcortical targets such as the pons and as far caudal as the pyramidal decussation and descending spinal tract and, importantly, do not extend axons to inappropriate targets such as the superior colliculus (SC). ES-NPCs transplanted into the visual cortex extend axons to the dorsal aspect of the SC and pons but avoid ventral SC and the pyramidal tract, whereas cells transplanted deep into the somatosensory cortex project axons to the ventral SC, avoiding the dorsal SC. Thus, these data establish that ES-derived cortical projection neurons can integrate into anatomically relevant circuits.
\end{abstract}

\section{Introduction}

Embryonic stem (ES) cells have attracted much attention as a limitless source to create the myriad of cell types found in the body. The finding that neurons can be generated from ES cells (ESCs) has led to the expectation that neurological conditions such as Parkinson's disease, amyotrophic lateral sclerosis (ALS), stroke, or spinal cord injury will be treatable using cell-based transplantation strategies (Muotri and Gage, 2006; Suzuki and Svendsen, 2008). However, the complexity of neuronal subtypes and connectivity within the CNS makes it increasingly apparent that multiple facets of the physiological and anatomical phenotype of a neuron will need to be recapitulated before their use in a clinical setting will be realized (Svendsen et al., 2001).

An important characteristic of neuronal function is the extension of axons in a very stereotypic and selective manner to other brain regions in which stable synaptic connections are formed onto the dendrites of postsynaptic neurons. It is these connections that endow the brain with its computational abilities, and correct connectivity between transplanted ES-derived neurons

Received Aug. 28, 2009; revised 0ct. 27, 2009; accepted Nov. 5, 2009.

This work was supported by National Institute of Neurological Disorders and Stroke Grants NS056138 and NS043879, Roman Reed Spinal Cord Injury Research Fund RR07-197, and California Institute for Regenerative Medicine Grant RC1-00134 (T.D.P.).

Correspondence should be addressed to Dr. James M. Weimann, Department of Neurology, Stanford Medical School, MSLS P256, 1201 Welch Road, Stanford, CA 94305-5489. E-mail: jweimann@stanford.edu.

M. Ideguchi's present address: Department of Neurosurgery, Yamaguchi University School of Medicine, 1-1-1 Minami-kogushi, Ube, Yamaguchi 755-8505, Japan.

D0I:10.1523/JNEUROSCI.4318-09.2010

Copyright $\odot 2010$ the authors $\quad$ 0270-6474/10/300894-11\$15.00/0 and the host circuitry is a critical step in restoring circuit integrity and behavioral function. To date, some characteristics of cortical neurons have been reported in ES-derived cells such as neurotransmitter phenotype, gene expression, and rudimentary synapse formation (Brüstle et al., 1997; Wernig et al., 2004; Muotri et al., 2005). However, establishment of the correct dendritic (Konur and Ghosh, 2005) and axonal connectivity (O'Leary and Koester, 1993; Larsen and Callaway, 2006) of transplanted ESderived neurons in the mammalian cerebral cortex has not been well established.

The cortex is partitioned into distinct regions that subserve different functions such as vision, touch, hearing, and movement. Each of these areas is composed of six layers of glutamatergic pyramidal neurons, which comprise $\sim 80 \%$ of the total number of neurons. The pyramidal neurons in each of the six layers are characterized by distinct firing patterns, axonal and dendritic projection patterns (Connors and Gutnick, 1990; Tseng and Prince, 1993), and gene expression profiles (Hevner, 2006). Of interest are the neurons in layers 5 and 6 that comprise the corticofugal pathways and of particular clinical relevance are the corticospinal motor neurons that transmit information from the cortex to the spinal cord to control muscle function. It is these neurons that are lost in ALS (Boillée et al., 2006) and spinal cord injury (Hains et al., 2003).

Two major classes of layer 5 neurons are born and migrate into the cortical plate at the same time during development (O'Leary and Koester, 1993). On arriving in the newly forming cortex, one class of layer 5 neuron extends axons to the contralateral cortex via the corpus callosum, whereas the other class ex- 
Table 1. Composition of media used to propagate ES, MS5 cell lines, and neural induction of ES cells on MS5 stromal cells

\begin{tabular}{|c|c|c|}
\hline Media & & Source \\
\hline \multicolumn{3}{|l|}{ ES cell culture media } \\
\hline GMEM & $500 \mathrm{ml}$ & Sigma-Aldrich; G5154 \\
\hline FBS & $10 \%$ & HyClone; SH30071.03 \\
\hline Glutamine & $2 \mathrm{~mm}$ & Invitrogen; 25030-081 \\
\hline NEAA & $0.1 \mathrm{~mm}$ & Invitrogen; $11140-050$ \\
\hline Sodium pyruvate & $1 \mathrm{~mm}$ & Invitrogen; 11360-070 \\
\hline 2-Mercaptoethanol & $55 \mu \mathrm{M}$ & Invitrogen; 21985-023 \\
\hline LIF & $2000 \mathrm{U} / \mathrm{ml}$ & Conditioned media \\
\hline Pen/Strep & $100 \mathrm{U} / \mathrm{ml}$ & Invitrogen; $15140-122$ \\
\hline \multicolumn{3}{|l|}{ MS5 culture media } \\
\hline$\alpha \mathrm{MEM}$ & $500 \mathrm{ml}$ & Invitrogen; 12571-063 \\
\hline FBS & $10 \%$ & Invitrogen; 16140-071 \\
\hline Pen/Strep & $100 \mathrm{U} / \mathrm{ml}$ & Invitrogen; 15140-122 \\
\hline \multicolumn{3}{|c|}{ MS5 and ES differentiation media } \\
\hline GMEM & $500 \mathrm{ml}$ & Invitrogen; 11710-035 \\
\hline KSR & $10 \%$ & Invitrogen; 10828-028 \\
\hline NEAA & $0.1 \mathrm{~mm}$ & Invitrogen; 11140-050 \\
\hline Sodium pyruvate & $1 \mathrm{~mm}$ & Invitrogen; $11360-070$ \\
\hline 2-Mercaptoethanol & $55 \mu \mathrm{M}$ & Invitrogen; 21985-023 \\
\hline Pen/Strep & $100 \mathrm{U} / \mathrm{ml}$ & Invitrogen; 15140-122 \\
\hline
\end{tabular}

Abbreviations: GMEM, Glasgow minimal essential medium; NEAA, nonessential amino acids; KSR, knock-out serum replacement; $\alpha M E M, \alpha$ minimum essential medium.

tends axons through the internal capsule to subcortical brain structures. Subcortical projecting layer 5 neurons from different regions of cortex all project a major axon into the pyramidal tract while extending collateral axons to the colliculus and pons. After birth, these neurons start to refine their axonal projections in an area-specific manner such that neurons from visual and somatosensory cortex retract the portion of axon in the spinal tract but maintain collaterals to superior colliculus and pons. Corticospinal motor neurons lose their collaterals to colliculus but maintain collaterals within pons and keep extending their axons down the spinal cord. Thus, the mature pattern of connectivity from layer 5 neurons to subcortical targets is the outcome of refinement of initially exuberant projections and is thought to be activity dependent (Luo and O'Leary, 2005).

In this report, we demonstrate that ES cells can be induced to differentiate into cortical projection neurons. This requires specific patterning in vitro that is facilitated by coculture with MS5 stromal cells. The ES-neural precursor cells (ES-NPCs) can differentiate into layer 5 cortical neurons when transplanted in the neonatal mouse cerebral cortex. Axons from these neurons acquire a cortical area-specific projection pattern that recapitulates the normal adult structure necessary for integrating incoming signals, computing, and outputting to other brain regions.

\section{Materials and Methods}

Cell culture. The ES cell line E14Tg2a.4 was cultured as described by Friedel et al. (2005) without the need of a feeder layer. Vector constructs containing CMV (cytomegalovirus) $\beta$-actin driving enhanced green fluorescent protein (eGFP) [50 $\mu$ g; CA-eGFP-mut4 (Okada et al., 1999)] and pGKneo $(5 \mu \mathrm{g})$ were linearized and electroporated into $10^{7}$ cells. Cells were plated at low density, $10^{6}$ per $10 \mathrm{~cm}$ dish coated with gelatin (Millipore Bioscience Research Reagents; ES-006-B) for $10 \mathrm{~d}$ in ES cell media (Table 1) under Geneticin selection $(125 \mu \mathrm{g} / \mathrm{ml}$; Invitrogen; 11811). Colonies $(n=96)$ were selected based on the intensity of eGFP fluorescence. Two clones F7 and C7 were chosen based on their sustained expression level of eGFP and their ability to differentiate into the three main neural lineages, neurons, astrocytes, and oligodendrocytes after neural induction.
Table 2. Antibodies used in this study, dilution, and source

\begin{tabular}{lll}
\hline Antibody & Dilution & Source \\
\hline$\beta$-Tubulin-III & $1: 600$ & Covance Research Products; PRB-435P \\
CNPase & $1: 200$ & Sigma-Aldrich; C5922 \\
Ctip2 & $1: 500$ & Abcam; ab18465 \\
GFAP & $1: 2000$ & Millipore Bioscience Research Reagents; AB5804 \\
GFP & $1: 2000$ & Invitrogen; A11122 \\
MAP2ab & $1: 500$ & Sigma-Aldrich; M1406 \\
NCAM & $1: 300$ & Millipore Bioscience Research Reagents; AB5032 \\
Nestin & $1: 300$ & BD Biosciences Pharmingen; 556309 \\
NeuN & $1: 200$ & Millipore Bioscience Research Reagents; MAB377 \\
0ct3/4 & $1: 100$ & Santa Cruz Biotechnology; SC-8628 \\
0tx1 & $1: 400$ & Abnova; H00005013-A01 \\
RC2 & $1: 200$ & DSHB; RC2-s \\
SSEA1 & $1: 400$ & DSHB; MC480-s \\
\hline
\end{tabular}

ES cells were induced to a neural precursor state by coculture with the mouse stromal cell line MS5 (Kirin Pharma) (Barberi et al., 2003) (Table 1). Briefly, a confluent plate of MS5 cells were treated with mitomycin C $(2 \mu \mathrm{g} / \mathrm{ml})$ for $2 \mathrm{~h}$, washed, dissociated, and plated onto gelatin-coated 10 $\mathrm{cm}$ dishes. The next day, $10^{4}$ ESCs were added and cultured in differentiation media for $7 \mathrm{~d}$ (Table 1). FGF2 (fibroblast growth factor 2) (R\&D Systems) at $20 \mathrm{ng} / \mathrm{ml}$ added for the last $2 \mathrm{~d}$ increased cortical pyramidal neuron numbers. ES-NPC colonies were removed by incubation in $\mathrm{Ca}^{2+}, \mathrm{Mg}^{2+}$-free HBSS (15 mM HEPES) for 30-45 min. These ES-NPC colonies were dissociated in papain (Worthington Biochemicals) for 20 min at $35^{\circ} \mathrm{C}$ and triturated into a single-cell suspension.

In addition, ES cells were induced to become NPCs using the $-4 /+4$ retinoic acid (RA) embryoid body (EB) method (EB-NPCs) (Bain et al., 1995). ES cells $\left(5 \times 10^{4} / \mathrm{ml}\right)$ were added to nonadherent $10 \mathrm{~cm}$ Petri dishes using ES cell media without leukocyte inhibitory factor (LIF) with media changes every $2 \mathrm{~d}$. Plates were tapped three to five times each day to minimize adhesion to the plates. RA was added on days 4 and 6 at $1 \mu \mathrm{M}$. After $8 \mathrm{~d}$, the embryoid bodies were dissociated in papain as noted above.

The dissociated ES-NPCs were either plated for immediate immunostaining or further differentiated into mature neural cells after plating $1.5 \times 10^{5}$ cells in $500 \mu \mathrm{l}$ of NB media (Neurobasal and B27; Invitrogen; 21103-049 and 1311570) in each well. Eight-well glass slides (Falcon; BD Biosciences Discovery Labware; 123456) were coated with polyornithine followed by fibronectin (Millipore; FC010) before use. The ES-NPCs were allowed to differentiate for $7 \mathrm{~d}$ and then fixed in $4 \%$ paraformaldehyde.

Immunohistochemistry. After fixation in $4 \%$ paraformaldehyde, followed by permeabilization and blocking with $0.3 \%$ Triton X-100 and $2 \%$ skim milk for cell cultures or $5 \%$ normal goat serum for brain sections, cells/sections were incubated at $4^{\circ} \mathrm{C}$ overnight in primary antibodies (Table 2). Appropriate cyanin-3 (Cy3)- and Cy5-labeled secondary antibodies (Jackson ImmunoResearch Laboratories) were used at room temperature for $2 \mathrm{~h}$. Green fluorescent protein (GFP) was visualized by its own fluorescence or with an anti-GFP primary antibody and FITC secondary antibody. For nuclear staining, 4',6-diamidino-2-phenylindole (DAPI) $(200 \mathrm{ng} / \mathrm{ml})$ was added to the final wash. The percentage of immunoreactive cells was evaluated using a laser confocal microscope (Zeiss LSM5). The cells in 10 fields were counted for four to seven independent cultures. The total number of cells was evaluated by counting DAPI-positive nuclei.

ES-NPC transplantation. Dissociated ES-NPCs were transplanted into the cerebral cortex of neonatal C57BL/6 (The Jackson Laboratory) or Swiss Webster (Charles Rivers) mice, aged postnatal day 1 (P1) to P3, following Stanford Administrative Panel on Laboratory Animal Care guidelines. Briefly, neonatal mice were anesthetized by submersion in ice water until the pups stopped breathing. The mice were then immobilized on wet gauze over an ice bed with the head in the horizontal position and a midline incision made. A small hole was drilled in the skull over the motor, somatosensory, or visual cortex. A fine-tipped, sterile glass pipette filled with ES-NPCs $(40,000 / \mu \mathrm{l})$ was positioned using a stereotactic device to a depth of $400 \mu \mathrm{m}$. Approximately 5000 cells were slowly in- 
troduced into the cortex over several minutes. The skin was closed with tissue adhesive (Vetbond; $3 \mathrm{M}$ ), and the pups were resuscitated under a warming lamp.

Two or 3 weeks after transplantation, mice were perfused transcardially. Brains were removed and sectioned at $60 \mu \mathrm{m}$ thickness. Freefloating sections were immunostained with the indicated primary antibodies and appropriate secondary antibodies, as described above. An anti-GFP antibody and diaminobenzidine (DAB) (Sigma-Aldrich; D5905) enhancement was used to visualize the dendrites and axons of GFP-positive neurons.

A reproducible and reliable sampling method was used to estimate the number of axons that invade subcortical targets after transplantation of ES-NPCs. After transplanting MS5-NPCs into the visual, somatosensory, or motor cortex, sections in the parasagittal plane were made, processed for GFP/DAB, and bright-field micrographs were taken of each section of the ipsilateral SC (usually 7-10 sections). The SC was divided into a dorsal (layer I-III) and a ventral (layers V-VII) region and a line drawn bisecting the anterior and posterior SC. Onto this image was superimposed the dark-field image of the axons (see Fig. 6), and the number of axons that cross this line was enumerated. Although this is probably an underestimate of the number of axons in the SC, this method provided an unbiased and reproducible assessment of axon distribution. The same method was used to count the axons in the pons, pyramidal decussation, and spinal tract (see Fig. 5).

Reverse transcription-PCR analysis. Total RNA was extracted from ESCs, E14 cortex, day 7 MS5-NPCs, day 8 EB-NPCs, and ES-derived neurons after an additional $7 \mathrm{~d}$ of differentiation, using RNeasy Mini-plus kit (QIAGEN). Total RNA $(1 \mu \mathrm{g})$ was reverse transcribed using oligo-dT primers with a Superscript II kit (Invitrogen). PCR was performed for 28 cycles using one-twentieth of the final cDNA from the reverse transcription. Primers were designed using FRODO primer selection (Rozen and Skaletsky, 2000) and when applicable spanned at least one intron to ensure amplification of cDNA and not genomic DNA. The primer sequences and melting temperatures are found in supplemental Table S4 (available at www.jneurosci.org as supplemental material).

Statistical analysis. Statistical analysis was performed using a commercially available software package (Statview 5.0; SAS Institute). Data were tested by one-way ANOVA and Bonferroni/Dunn's post hoc analysis or Student's $t$ test. Differences were considered statistically significant at $p<0.05$. Data are presented as means \pm SDs. All results were derived from three to seven independent experiments.

\section{Results}

Our goal was to establish protocols to generate long-distance cortical projection neurons that form the correct synaptic connectivity between stem cell-derived neurons and host neurons. We reasoned that embryonic stem cells must be induced into the appropriate state to differentiate correctly in the host brain as has been demonstrated for retinal and spinal cord motor neurons (Wichterle et al., 2002; Lamba et al., 2009). During development, presumptive cortical NPCs receive inductive signals from the definitive endoderm and Hensen's node as early as gastrulation (Beddington and Robertson, 1998; Stern, 2005). Guided by the developmental principles of normal development, we reasoned that neural induction of ES cells that resulted in NPCs with fea- tures of cortical progenitors would be needed for transplantation since after the animal is born many of these inductive signals are no longer present. Additionally, the induced-ES neurons should not be so mature that they can no longer respond to the local environment. Therefore, a neural induction method that recapitulates the state of neural precursors during early cortical development and limits the number of tumor-producing cells should provide the optimal source of transplantable cells.

\section{In vitro characterization of ES-NPCs and mature neurons}

Two methods to neuralize ES cells have gained popularity: retinoic acid neural induction, involving the formation of EB-NPCs, and a feeder layer-dependent method (coculture with the MS5 stromal cell line) that mimics organizing principles used during development to generate neural precursors (MS5-NPCs). The first method is loosely based on previous observations that ES cells tend to default into a neural lineage at low density and will form aggregates of cells enriched for neural progenitor cells (Tropepe et al., 2001). In a recent adaptation, ES cells are allowed to proliferate in suspension without LIF, forming small spheres of cells in $4 \mathrm{~d}$. Addition of retinoic acid for an additional $4 \mathrm{~d}$ differentiates the cells toward a neural precursor lineage (Bibel et al., 2004). A less well characterized induction method involves plating dissociated ES cells on a confluent layer of MS5 cells. After $6 \mathrm{~d}$ of coculture, large colonies of ES-derived neural precursor cells were observed. Few cells within the colonies expressed Oct3/4, an ES cell marker (Fig. 1 $A, D$ ), whereas the majority of the cells $(80 \%)$ expressed the proliferative marker nestin (Fig. $1 B, E)$. Approximately $30 \%$ of the cells within the colonies expressed $\beta$-III 

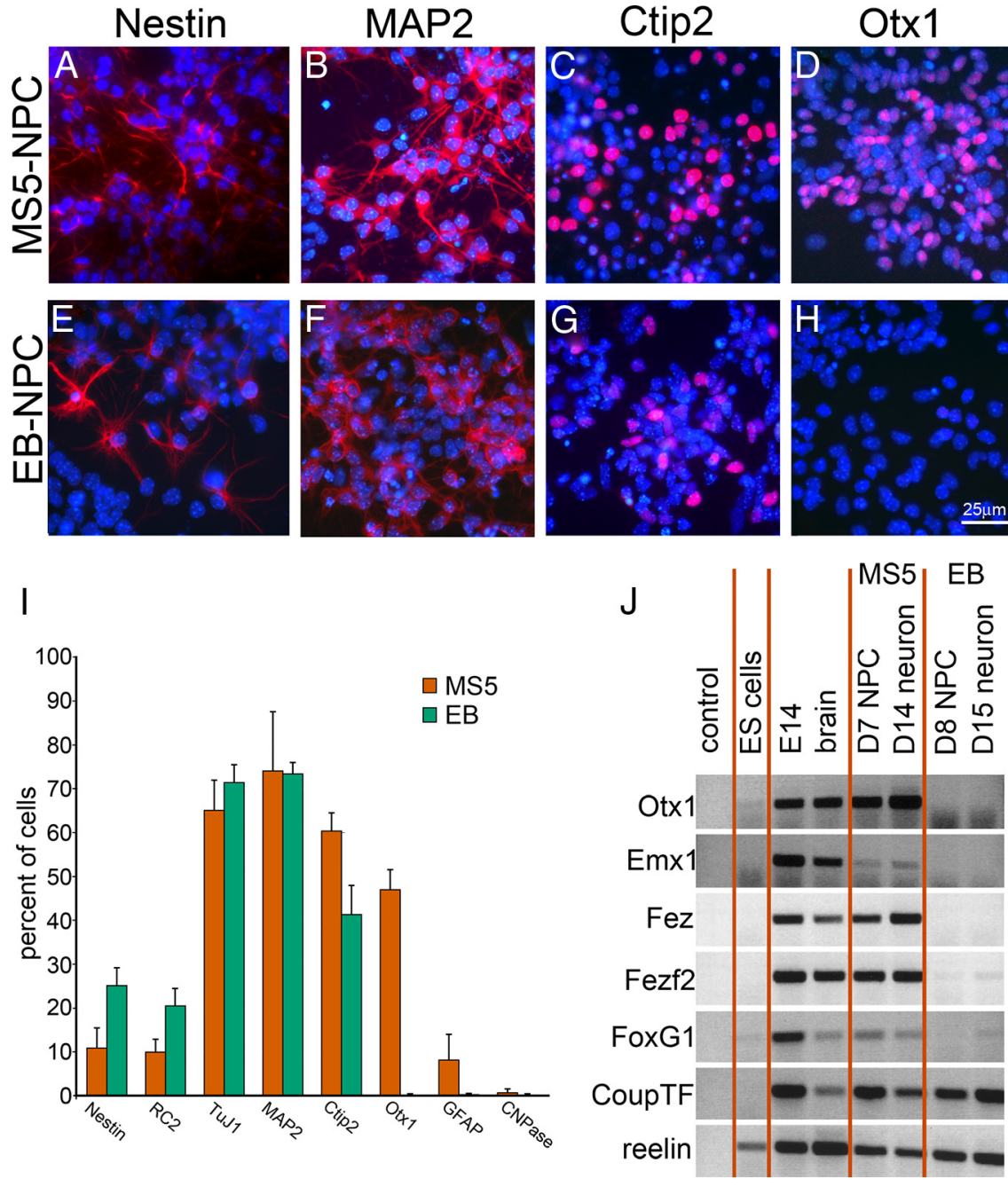

Figure 2. MS5-NPCs but not EB-NPCs generate cortical pyramidal neurons in vitro. $\boldsymbol{A}-\boldsymbol{D}$, Immunostaining of day 6 MS5-NPCS after an additional $7 \mathrm{~d}$ of differentiation into mature cells on polyornithine/fibronectin (OF)-coated slides. $\boldsymbol{E}$ - $\boldsymbol{H}$, Immunostaining of day 8 EB generated NPCs after an additional $7 \mathrm{~d}$ of differentiation on OF-coated slides. $\boldsymbol{A}, \boldsymbol{E}$, Nestin. $\boldsymbol{B}, \boldsymbol{F}, \mathrm{MAP2}$. C, G, Ctip2. D, $\boldsymbol{H}$, 0tx1. Note, in $\boldsymbol{H}$, no 0tx1 staining of EB-NPCs. Scale bar, $25 \mu \mathrm{m}$. I, Frequency distribution of several neural markers as a percentage of total DAPI stained cells in $7 \mathrm{~d}$ neuronal differentiation cultures on OF slides after either MS5 or EB NPC induction $(N=5)$ (Nestin, RC2, Ctip2, 0tx1, $p<0.001$; GFAP, $p=0.004$; TuJ1, MAP2, and (NPase, no difference). Error bars indicate SD. J, RT-PCR profile of five genes expressed in embryonic cortex (E14 brain) as well as MS5-NPCs/mature neurons but not expressed in EB-generated NPCs or neurons $(N=4)$. CoupTF is an example of 10 genes that are expressed in both conditioning protocols. Reelin is an example of 11 genes expressed in all cells (supplemental Table S1, available at www.jneurosci.org as supplemental material).

tubulin (TuJ1), an early marker for neurons (Fig. 1C,F). The vast majority of the colonies did not contain any Oct3/4positive cells, suggesting that these MS5-derived neural cells would result in a low frequency of tumor formation after transplantation.

To characterize the dynamics of neural patterning on the MS5 stromal cells, cultured ES cells were removed from the MS5 feeder layer, dissociated, and immunostained, over an $8 \mathrm{~d}$ time course. The majority of cells express nestin and RC2, a radial glial/neural progenitor marker (Fig. 1G,H) (80\% of total cells). Oct3/4- and stage-specific embryonic antigen-1 (SSEA-1)positive cells, which are thought to underlie teratoma formation (Morizane et al., 2006), rapidly decreased to nearly zero (Fig. 1I). Also, nestin-positive cells increased dramatically during the first $5 \mathrm{~d}$ of culture, plateaued, and then started to decrease as other mature progeny, expressing neuronal markers such as neural cell adhesion molecule (NCAM), $\beta$-III tubulin (TuJ1), and neuronal nuclei (NeuN) started to represent a greater percentage of cells
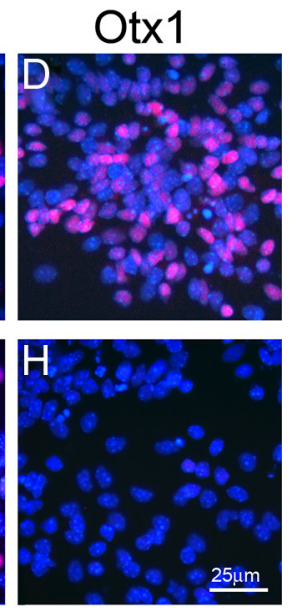

(Fig. 1I). For subsequent experiments, we chose day 6 or 7 of coculture because of the greatest percentage of nestin-positive cells, indicative of a neural stem cell, and the number of potentially tumor-forming Oct 3/4- and SSEA1-positive cells is minimal. EB-NPCs were used at day 8 as a comparator (Bibel et al., 2004).

We next examined the potential of these MS5-NPCs to differentiate into more mature classes of cells such as neurons and glia. The ES cultures were induced as above, dissociated, and further differentiated for an additional $7 \mathrm{~d}$ on coated slides in Neurobasal before immunohistochemistry processing. Interestingly, more immature progenitor-like cells expressing nestin and RC2 were seen in the EB-NPC population than the MS5-NPC population $(p<$ 0.001 for nestin and RC2) (Fig. 2I), suggesting that maturation of EB-NPCs into neurons is less effective and may explain the propensity of these cells to form tumors on transplantation. These nestinand RC2-positive cells typically occurred in clusters, suggesting that they arose from clones (Fig. 2A,E). Moreover, no tumor formation was evident in three animals transplanted with MS5-NPCs that were allowed to survive for 12 months. In contrast, EB-NPC-transplanted animals typically had evidence of tumors by 3 months (six of six animals at 3 months). The two major glial subtypes, astrocytes and oligodendrocytes, were nearly absent from both conditions, but a few clones emerged in the MS5 condition. The two markers used to distinguish mature neurons, TuJ1 and MAP2, did not show a difference between the two conditions and represented $\sim 70 \%$ of the total cell population, suggesting that the major cell type generated is a neuronal derivative (Fig. $2 B, F, I$ ). The percentage of glutamatergic $(80 \%)$ and GABAergic neurons (20\%) appear to be similar in both conditioning methods.

Two gene markers that distinguish subcortical projection neurons from other classes of cortical pyramidal neurons were examined. Interestingly, both MS5 (60\% of cells) and EB ( $41 \%$ of cells) induced neurons expressed Ctip2, a transcriptional repressor that is required for the manifestation of subcortical axons in mice (Arlotta et al., 2005) (Fig. 2C,G). Although a statistical difference was noted (Fig. $2 I)(p<0.001)$, the high frequency in both populations made it unlikely to be of biological significance.

The most prominent difference between the two populations of cells is the absence of Otxl expression in the EB-NPC population. Otxl is a transcription factor that has been implicated in telencephalon development and is highly expressed in the class of layer 5 neurons that project to subcortical targets (Frantz et al., 1994; Weimann et al., 1999). Nearly $50 \%$ of the MS5-NPC-differentiated cells expressed Otx1, whereas we did not observe any Otxl expression in EB-NPC-generated neurons (Fig. 2D,H,I). These results suggest 
that the preconditioning regimen can fundamentally alter the fate of the resulting neural precursors.

The expression of 34 genes known to be expressed in the brain were compared by reverse transcription (RT)-PCR to determine whether other gene products in addition to Otxl were differentially expressed in the two populations of cells (supplemental Table S1, available at www. jneurosci.org as supplemental material) as several transcription factors are required for correct corticofugal projections (Arlotta et al., 2005; Chen et al., 2005; Molyneaux et al., 2005). Many of the genes evaluated were detectable at all stages of differentiation [e.g., in ES cells, embryonic day 14 cortex (E14 brain), day 7 MS5-NPCs, day 8 EB-NPCs, as well as in day 7 differentiated cultures of neurons from MS5 and EB neural precursors (D14 MS5 neuron and D15 EB neuron)]. Sixteen of the genes, as exemplified by COUP-TF, were expressed in E14 brain as well as both neural-induced ES cells. Of interest were five genes that were expressed in E14 brain, MS5-induced NPCs, and MS5-derived neurons but were not expressed in EB-induced cultures at either the stage of NPCs or more terminally differentiated neuron (Fig. 2J). All five genes, Otx1, Emx1, Fezf2, Fez, and FoxG1, are known to play a role in forebrain development or axon guidance, and we hypothesized that this difference in patterning is likely to generate cortical projection neurons.

\section{MS5-induced neurons project axons to subcortical brain structures}

Deep layer neurons (layers V and VI) of sensory/motor cortex extend a robust axon tract to spatially distinct subcortical brain structures such as the thalamus, colliculus, pons, and spinal cord. We exploited this fact to test whether the different in vitro neural patterning methods would generate ES-derived neurons with the capability to extend axons to subcortical areas and thus fulfill a criterion for an important class of a cortical pyramidal neuron.

When 5000 dissociated EB-NPCs were transplanted into the cortex of postnatal mice, they further differentiated into mature neurons with elaborate dendrites and axons (Fig. 3A). GFP expression can be accentuated by histological staining with a GFP antibody and $\mathrm{HRP} / \mathrm{DAB}$ reaction. The DAB precipitate appears golden brown when viewed with dark-field optics. Individual axons can be readily observed even at low magnification (Fig. $3 A$ ). Although these neurons project axons extensively to other cortical areas, we observed very few axons entering the internal capsule, which is the primary route for axon invasion of subcortical targets $(11.0 \pm 11.6$ axons per a transplanted hemisphere) (Fig. $3 A, C$ ). This suggests that, although the embryoid bodyretinoic acid method of neural induction generates neurons, very few expressed this critical phenotype of a subcortical projecting cortical pyramidal neuron.
MS5-NPC
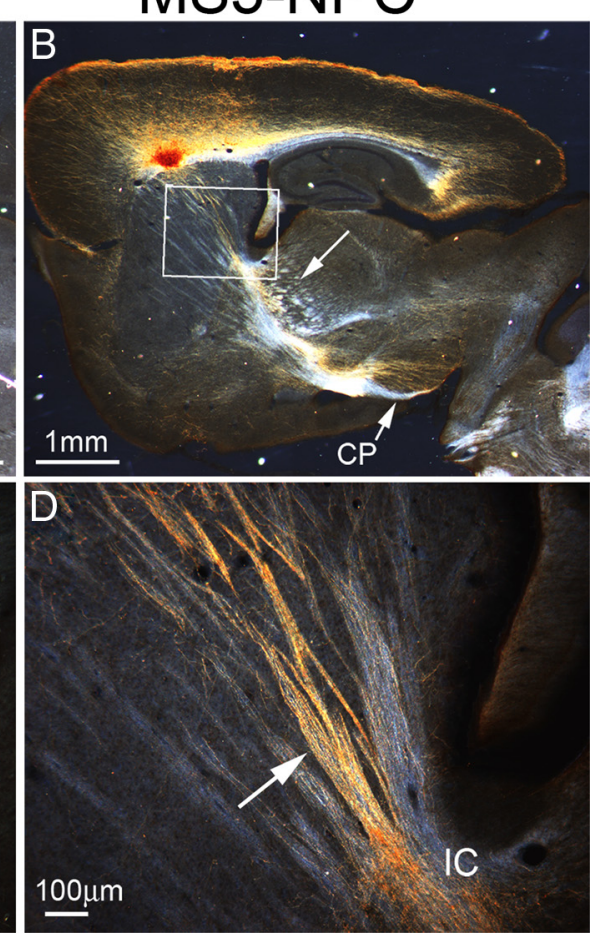

Cortex
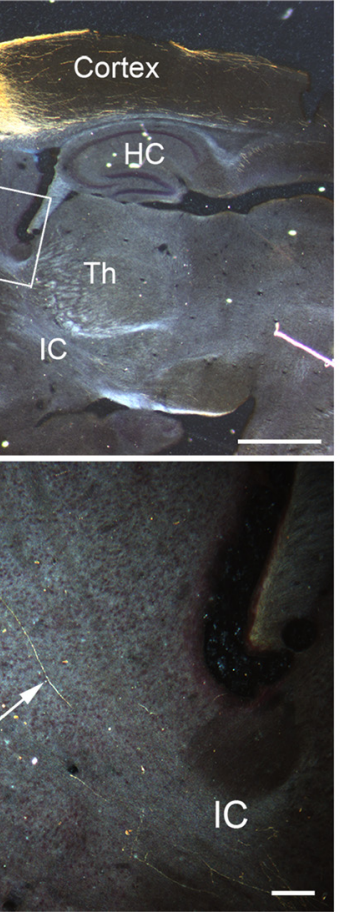

눈

Figure 3. MS5 preconditioned ES-derived neurons project axons to subcortical areas. GFP ${ }^{+}$ES cell-derived NPCs were transplanted 作

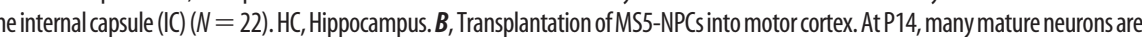
(arrow), and cerebral peduncle (CP) (arrow) (N=48).C, High-powe 列 hemisphere was observed (7-8 sections). $\boldsymbol{D}$, High-power image of the boxed area in $\boldsymbol{B}$; hundreds of axons are apparent in fasciculated bundles entering the IC (arrow). Scale bars: $A, B, 1 \mathrm{~mm} ; C, D, 100 \mu \mathrm{m}$.

We next examined NPCs generated from coculture with the MS5 stromal cell line. After transplantation of the same number of MS5-NPCs, the differentiated neurons projected profuse bundles of fasciculated axons through the striatum and into the internal capsule (Fig. 3B). Hundreds of axons were seen extending along axon tracts in the striatum and converging in the internal capsule in this section (Fig. 3D). In fact, so many axons were observed that counting was impractical. These axons continued to subcortical targets such as the thalamus, pons, superior colliculus, and the spinal cord. These results suggest that there was a significant difference in the fate of the induced neurons using these two methods with mesodermal induction providing critical anterior neurectodermal patterning that is missing in the more popular direct EB-NPC induction methods.

\section{MS5-NPCs differentiate into cortical pyramidal neurons after transplantation: local neuronal morphology}

Although in vitro differentiation and marker expression has been considered adequate for determining neuronal specification, we sought to more stringently test cell fate decisions by transplanting the ES-derived NPCs into the cortex and evaluating the anatomical architecture of the resultant neurons. Cortical pyramidal neurons exhibit several distinguishing characteristics such as an apical dendrite that extends toward the pial surface and basal dendrites that branch profusely mainly within their resident layer (Larsen and Callaway, 2006). We sought to determine whether the transplanted ES-derived neurons possessed the dendritic structure of the major classes of cortical neurons (Koester and O’Leary, 1992). 

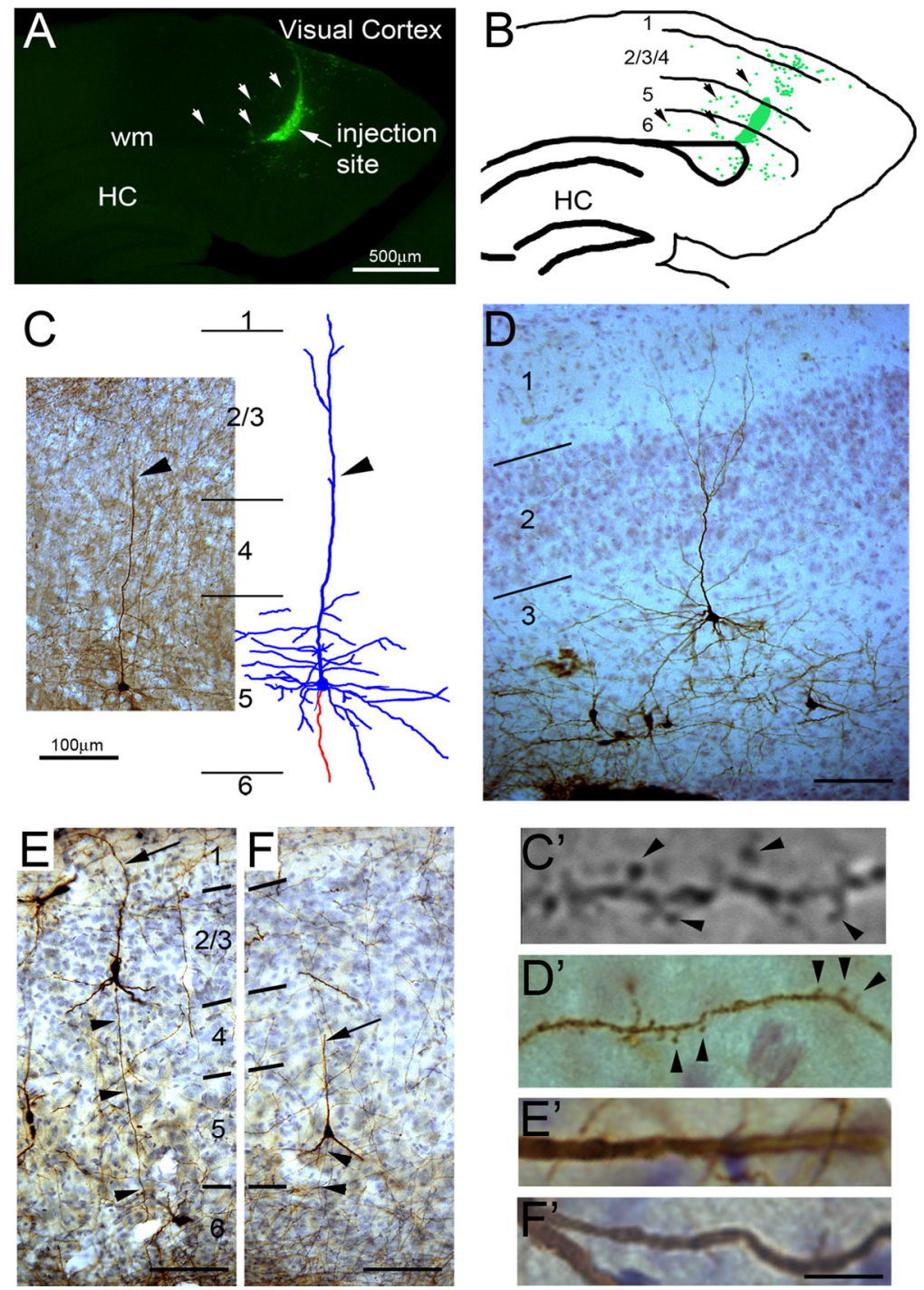

Figure 4. ES-derived neurons acquire mature cortical pyramidal neuron morphology after transplantation. $\boldsymbol{A}$, Parasagittal section of a P21 brain showing injection site of GFP-expressing MS5-NPCs in the deep layers of visual cortex. The arrows point to neurons that have migrated from the injection site into the parenchyma. wm, White matter; HC, hippocampus. B, Camera lucida drawing of injection site showing bolus of cells at the injection site and dispersed neurons around the injection. $\mathbf{C}$, GFP-labeled MS5-NPC-derived layer 5 pyramidal neuron in somatosensory cortex with camera lucida drawing (dendrites in blue; axon in red). The apical dendrite (arrowhead) is found in the adjacent section. $\boldsymbol{D}$, GFP-labeled MS5-NPC-derived layer 3 neuron in pyriform cortex. $\boldsymbol{E}, \boldsymbol{F}$, GFP-labeled EB-NPC-generated neurons in layer $2 / 3(\boldsymbol{E})$ and layer $5(\boldsymbol{F})$. Arrowhead, Basal directed axon. Arrow, Apical dendrite. $\boldsymbol{C}^{\prime}, \boldsymbol{D}^{\prime}$, Dendrites from $\boldsymbol{C}$ and $\boldsymbol{D}$ showing synaptic spines (arrowheads). $\boldsymbol{E}^{\prime}, \boldsymbol{F}^{\prime}$, Dendrites from $\boldsymbol{E}$ and $\boldsymbol{F}$ showing lack of synaptic spines. Scale bars: $\boldsymbol{A}, \boldsymbol{B}, 1 \mathrm{~mm} ; \boldsymbol{C}, \boldsymbol{D}-\boldsymbol{F}, 100 \mu \mathrm{m} ; \boldsymbol{C}^{\prime}, 5 \mu \mathrm{m} ; \boldsymbol{D}^{\prime}, \boldsymbol{E}^{\prime}, \boldsymbol{F}^{\prime}, 10 \mu \mathrm{m}$.

Most injection sites consisted of a bolus of cells that were tightly packed together and as a population extended dendrites toward the pial surface, which made it difficult to distinguish and reconstruct individual $\mathrm{GFP}^{+}$neurons (Fig. 4A,B). However, some transplanted cells migrated away from the injection site and differentiated in the parenchyma (Fig. $4 A, B$, arrows). In most animals, $\sim 5-10$ pyramidal neurons could be found at a distance from the injection site so that their dendritic and to some extent local axonal structure could be discerned. We also examined these cells for evidence of cell fusion between transplanted $\mathrm{GFP}^{+}$cells and host neurons and ruled out the possibility of rare fusion events to account for these observations (supplemental Fig. S1, available at www. jneurosci.org as supplemental material). Several features of deep layer cortical pyramidal neurons were apparent in these cells. First, these cells extended a primary apical dendrite toward the pial surface as exemplified in Figure 4C, in which a MS5NPC-derived layer 5 pyramidal neuron is shown in bright field (left) and camera lucida (right). The large apical dendrite extends to and branches in layers 1 and 2, whereas the basal dendrites branch profusely in layer 5 . In other cortical areas, this apical dendrite is seen in layers 2 and 3 neurons (Fig. $4 D$ ) as well as layer 6 neurons. These dendrites all have another characteristic of cortical pyramidal neurons, namely, synaptic spines protruding from the dendrites (Fig. $4 C^{\prime}, D^{\prime}$ ). The manifestation of dendritic spines suggests that these ESderived neurons are synaptically connected to other glutamatergic neurons in the cortex. Interestingly, we did not observe many GFP-axon onto GFP-synaptic spine connections, which suggests that the majority of these presumptive presynaptic connections are between host neurons and transplanted ES-derived neurons. Although all of the MS5-derived pyramidal neurons possessed synaptic spines, they appeared at a lower density than wild-type layer 5 and 6 pyramidal neurons. We have not been able to completely reconstruct the local axonal morphology of these cells because of the profuse axons from the adjacent injection bolus.

Neurons generated by the EB method also produced pyramidal-shaped neurons after transplantation into the cortex (Fig. $4 E, F)$. In striking contrast to pyramidal neurons described after MS5 neural induction, we have not observed any cells bearing synaptic spines ( 0 of 50 pyramidal-shaped EB-neurons) (Fig. $\left.4 E^{\prime}, F^{\prime}\right)$. These results suggest that, although the EB neural induction method can generate neurons that have pyramidal-shaped somata, these neurons do not have synaptic spines and are unlikely to be authentic cortical glutamatergic neurons.

\section{Specific axonal targeting of \\ MS5-derived neurons}

Layer 5 tufted pyramidal neurons from cortical regions subserving sensory, motor, and visual functions project to specific, nonoverlapping subcortical targets. If ES cells have successfully differentiated into fully competent cortical pyramidal neurons, they should project differentially to subcortical targets contingent on the cortical area in which they are transplanted. Since the utilization of postnatal recipient mice allows specific targeting to visual, sensory, and motor cortex, we assessed axonal targeting of MS5-NPC cells after selective placement in these areas (Fig. 5A). After transplantation of ES-derived NPCs into either the visual, somatosensory, or motor cortex, we counted the number of axons in the pons, pyramidal decussation, and the spinal tract at approximately C3-C4 (Fig. 5B). When MS5-NPCs are transplanted into the visual cortex, a robust projection of axons can be observed in the pons (Fig. $5 A, B, E$ ), which has been reported for 

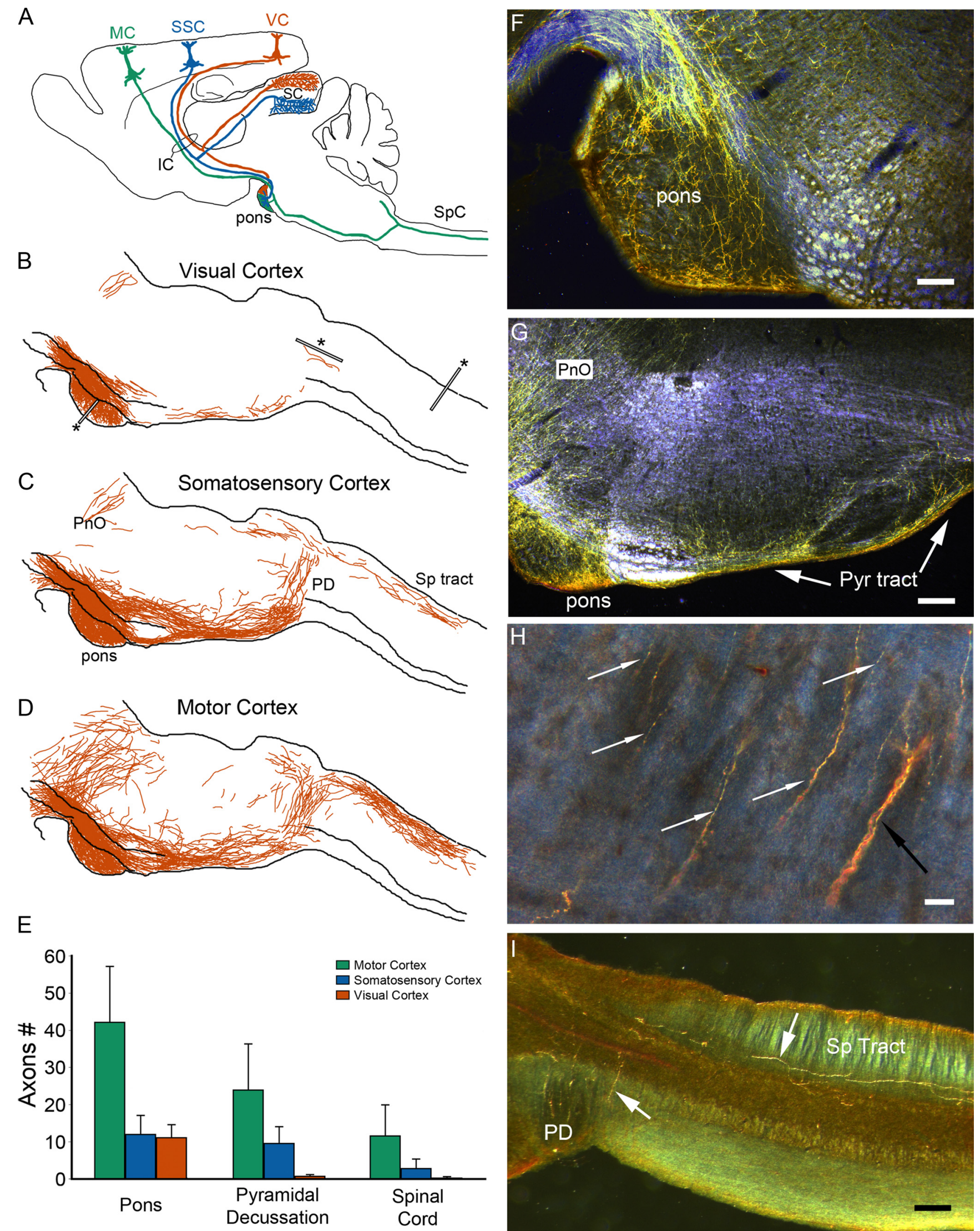

Figure 5. ES-derived neurons axonal projection to pons and spinal cord is cortical areal specific. $\boldsymbol{A}$, Diagram showing areal-specific axonal projection pattern of layer 5 neurons in motor cortex (MC) (green), somatosensory cortex (SSC) (blue), and visual cortex (VC) (red). Camera lucida composite drawing from seven to nine sections of MS5-NPC axons from cells transplanted into VC (B), SSC (C), and MC (D). $\boldsymbol{E}$, Enumeration of axons at the pons, pyramidal decussation (PD), and spinal tract marked by bar and asterisk in $\boldsymbol{B}$. No difference was observed between VCand SSC transplants, whereas MC cells showed more axons to all three locations (ANOVA, $p<0.001$ ) (supplemental Table S2, available at www.jneurosci.org as supplemental material). $\boldsymbol{F}$-I, Axons from MC transplant invade the pons (F), the pyramidal tract (Pyr tract) $(\boldsymbol{G})$, cross the midline at the pyramidal decussation $(\boldsymbol{H})$, and descend the spinal cord (Sp tract) (I). (Axons are gold in appearance; arrow point to axons.) Error bars indicate $S D$. Scale bars: $\boldsymbol{F}, 100 \mu \mathrm{m} ; \boldsymbol{G}, \boldsymbol{I}, 250 \mu \mathrm{m}$; $\boldsymbol{H}, 10 \mu \mathrm{m}$. IC, Internal capsule; PnO, pontine reticular nucleus; SpC, spinal cord. 


\section{ES-derived NPC transplanted in}

Motor Cortex
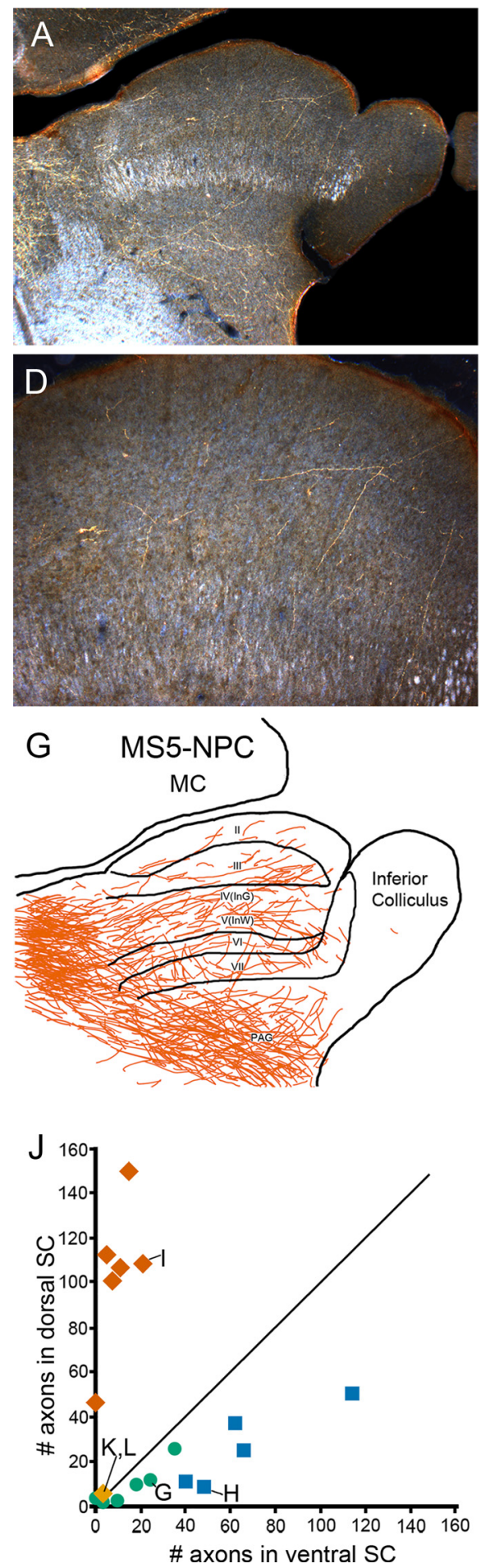

Somatosensory Cortex
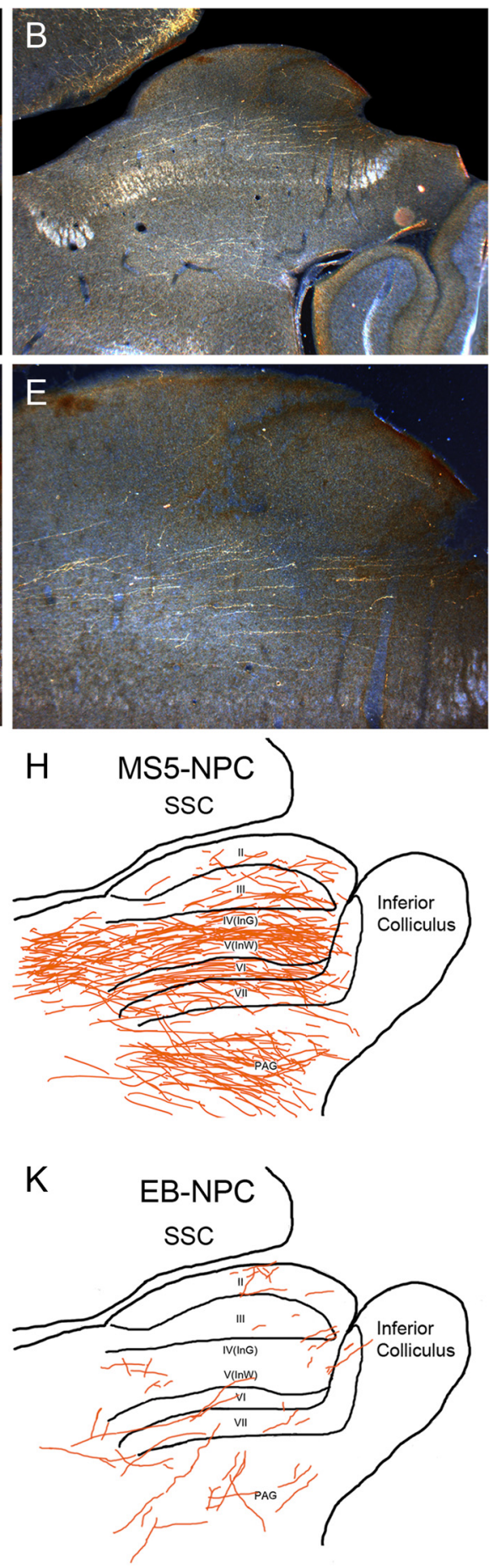

\section{Visual Cortex}
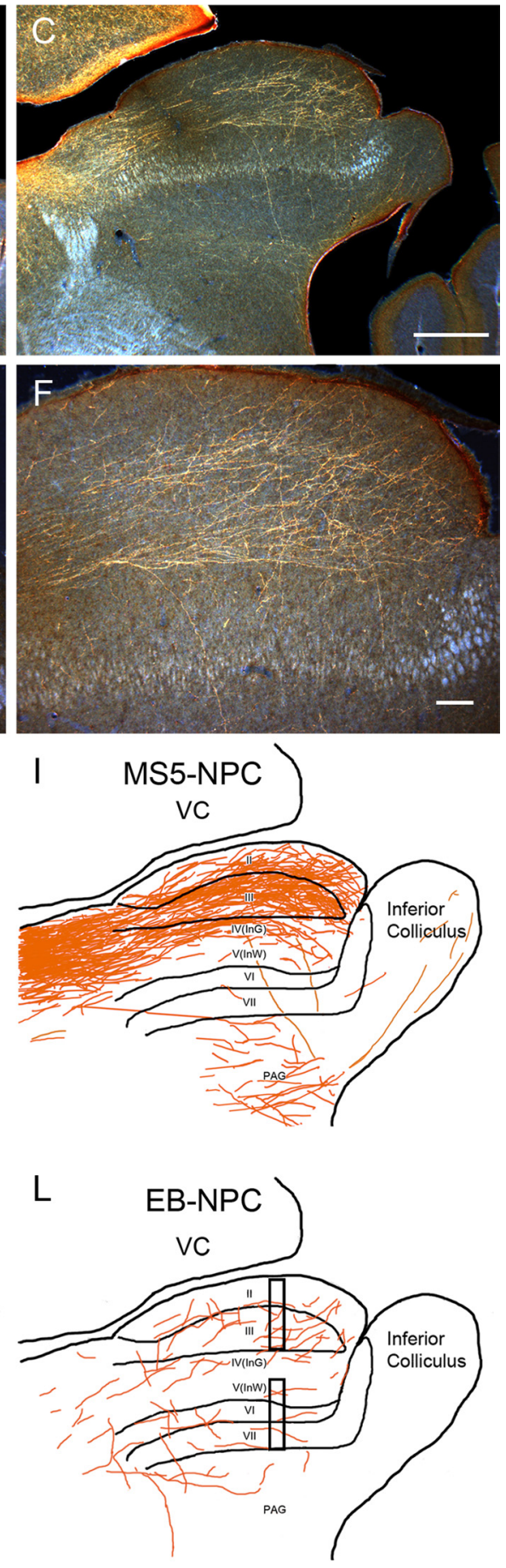

Figure 6. ES-derived neurons project axons to appropriate areas of superior colliculus. A-C, Axon projections in the SC from MS5-NPCs transplanted into the motor cortex (MC), somatosensory cortex (SSC), and visual cortex (VC). D-F, Enlargement of $\boldsymbol{A}-\boldsymbol{C}$. $\mathbf{G}-\mathbf{I}$, Camera lucida drawing of entire SC from $\boldsymbol{A}-\boldsymbol{C}$, respectively. Note that axons from visual cortex project preferentially to dorsal SC ( $\boldsymbol{I}$; layers I-III), whereas axons from somatosensory cortex project mainly to ventral $\mathbf{S C}(\boldsymbol{H} ; \mathrm{V}-\mathrm{VII})$.J, Distribution of counted axons crossing the midpoint of dorsal or ventral $S C(\boldsymbol{L}$, bars). The diagonal line represents random distribution. VC, Red diamonds (I points to brain in $\boldsymbol{I}$ ); SSC, blue squares $(\boldsymbol{H})$; and MC, green circles $(\boldsymbol{G})$. EB-NPCS rarely extend axons into SC (orange diamond; $\boldsymbol{K}, \boldsymbol{L}$ ). Number of axons in ventral SC was subtracted from dorsal SC, and a one-way ANOVA used ( $p<0.0001$ ) (supplemental Table $S 3$, available at www.jneurosci.org as supplemental material). $\boldsymbol{K}, \boldsymbol{L}$, EB-NPC transplant into SSC (K) or VC (L). Scale bars: $\boldsymbol{A}-\boldsymbol{C}, 500 \mu \mathrm{m} ; \boldsymbol{D}-\boldsymbol{F}, 100 \mu \mathrm{m}$. 
endogenous axons from normal visual cortex. Very few axons were observed in the pyramidal tract, fewer in the pyramidal decussation, and only a total of three axons was seen in the spinal cords of eight animals examined.

MS5-NPCs transplanted into the somatosensory cortex extended axons into the pons with the same frequency as the visual cortex transplants but in addition extended axons into the pyramidal tract. Many more axons were observed in the pyramidal decussation and even a few in the spinal tract (Fig. $5 A, C, E$ ). The most dramatic finding was that axons extending from MS5-NPCs transplanted into the motor cortex were able to pathfind to the pons (Fig. $5 A, D-F$ ), through the pyramidal tract (Fig. $5 G$ ), cross over to the contralateral spinal tract via the pyramidal decussation (Fig. $5 H$ ), and descend into the descending spinal tract as far as $\mathrm{C} 4$, the limit of our dissections (Fig. 5I). Thus, the axon projection pattern of transplanted MS5-NPCs in the different cortical areas recapitulated normal development and circuitry in a cortical area-specific manner.

In contrast, when EB-NPCs were transplanted into the visual, somatosensory, or motor cortices, only a few axons were observed as far caudal as the pons. None were seen in the pyramidal decussation or spinal cord. Even though these neurons had many of the characteristics of cortical neurons, their axons failed to navigate to correct subcortical targets.

The superior colliculus receives axons from the visual and somatosensory cortices and very few axons from the motor cortex. Layer $\mathrm{V}$ neurons from visual cortex extend axons to the most superficial layers of the super colliculus, whereas axons from the somatosensory cortex target the ventral layers of the SC (Dräger and Hubel, 1976). Remarkably, we found that projections were very appropriate. After transplantation of MS5-NPCs into the visual cortex, $>90 \%$ of axons projecting to the SC were found in the dorsal layers I-III of the superior colliculus and avoided the deeper layers of SC (Fig. 6C,F,I). Conversely, cells transplanted into the somatosensory area extended axons predominately into the ventral aspect of the SC (Fig. $6 B, E, H$ ). Consistent with the correct area-specific projection patterns, cells transplanted into the motor cortex mostly avoided the SC (Fig. $6 A, D, G$ ). Some axons were observed in ventral SC and are consistent with the heterogeneous nature of motor and somatosensory regions in the rodent cortex. A sampling of the number of axons within the dorsal and ventral SC for each animal is plotted, with the diagonal line representing random distribution (Fig. $6 J$ ). Thus, axons from visual cortex transplants (red diamonds) project to the dorsal SC while avoiding the ventral aspect $(n=6 ; p<0.001)$. Somatosensory cells (blue squares) preferentially project to the ventral SC, but some axons were observed in the dorsal SC $(n=5$; $p<0.001)$. The cells from motor cortex (green circles) projected sparse axons randomly to both the dorsal and ventral SC $(n=6$; NS). Only 2 of 18 animals transplanted with EB-NPCs had axons in the SC, and these few axons did not show a preference for dorsal or ventral SC (Fig. 6J-L).

These results strongly suggest that the ES cells differentiated on MS5 cells produced neurons that can respond appropriately to local cues within the cortex and as part of their differentiation program project axons to the correct subcortical targets, including the descending corticospinal tract.

In summary, these data show that ES cells preconditioned with MS5 stromal cells can lead to the neural induction of cortical pyramidal neurons. When these MS5-NPCs were transplanted into the cerebral cortex, they acquired the morphological phenotype characteristic of the particular cortical area in which they matured by sending long-distance axons to appropriate subcor- tical targets. Of particular clinical interest (ALS and spinal cord injury) is that these ES-derived pyramidal neurons were capable of growing axons into the descending corticospinal tract.

\section{Discussion}

Developmental programs expose stem and progenitor cells to a complex pattern of spatial and temporal cues, the timing and location of which critically regulate cell fate and function. In the CNS, rostral-caudal and dorsal-ventral patterning specifies both neuronal transmitter subtype and projection patterns of the developing neurons. This fine spatial patterning ultimately defines function. Although several previous studies have documented that ES cells, conditioned in various ways, can differentiate into generic neurons in the cortex and hippocampus after transplantation, it has been difficult to evaluate whether these cells were correctly patterned to connect and function appropriately for their location (Muotri et al., 2005; Eiraku et al., 2008; Gaspard et al., 2008). Without such evidence, it is difficult to evaluate the utility of a given approach or the potential for using these cells for replacement strategies, especially in the clinical sphere, in which inappropriate connectivity can lead to suboptimal outcomes. Here, we show that in vitro patterning of ES cells is a critical variable in generating specific neuronal subtypes and that ES cells can be induced to become cortical projection neurons that project long-distance axons to appropriate subcortical targets. We suggest that the MS5 neural induction method specifies the ES cells to a neural precursor state that resembles early cortical progenitors at approximately embryonic day 12-13 and on transplantation local cues within the developing cortex further specify the cells to become areal-specific cortical neurons as has been suggested by heterotopic transplantation studies (O'Leary et al., 1995).

\section{Connectivity: an important feature of neurons}

What are the most important attributes of a neuron? Although gene expression and somata shape have been used as a proxy for neuron specification, it is the connections among neurons that are their defining characteristic and are obligatory to produce relevant behaviors. During embryonic development, neurons from sensory/motor areas project a major axon toward the spinal cord and sprout exuberant collaterals to several target areas that are later pruned to the final adult pattern (O'Leary and Koester, 1993). We chose a time point, postnatal week 2-3, when the final adult axonal pattern is well established to minimize the confounding process of refinement of exuberant projections. This raises an interesting point of whether the transplanted ESderived neurons also project to multiple subcortical areas and then refine their axons in an areal-specific manner. Analysis at different time points may reveal that ES-derived neurons recapitulate this developmental behavior.

It is interesting to note that, although the extensive $\mathrm{GFP}^{+}$ axonal projections observed in the periaqueductal gray matter (PAG) of the central gray of the midbrain (Fig. 6) is not what would be expected from neurons within the motor/sensory cortices, there are two possible explanations that can account for these apparently mistargeted axons. First, these axons may be attributable to aberrant targeting of axon collaterals from transplanted neurons from motor/sensory cortex. However, equally compelling, is the possibility that the $\mathrm{GFP}^{+}$axons observed in the PAG may be from a subset of induced ES-derived neurons with characteristics of frontal agranular cortex and that they are faithfully projecting axons to their correct subcortical target. Studies in rodents demonstrate a class of layer 5 neurons from the 
agranular frontal cortex (orbital, insular, prelimbic, and anterior cingulated cortices) that project axons to the central gray area and mediate behaviors such as analgesia, aversion, and reward (Hardy and Leichnetz, 1981; Reep et al., 1987). Future experiments using retrograde tracer to highlight which cells project to each subcortical location will be need to resolve this question.

Understanding the dynamics of ES-derived axon pathfinding and guidance will have clinical implications since the transplanted cells must be capable of following already established pathways in adults. Placing cortical explants of embryonic cortex into damaged adult motor cortex has revealed that some transplanted neurons can extend axons into the spinal cord, suggesting that even in the adult CNS new axons can grow very long distances (Gaillard et al., 2007), and is encouraging for the prospects of using ES-NPCs in adults.

Synaptic spines are a prominent characteristic of cortical pyramidal neurons. Although a small population of corticothalamic and corticostriatal pyramidal neurons has been reported to lack spines, the vast majority manifest a profusion of spines along their dendrites (Gao and Zheng, 2004; Hattox and Nelson, 2007). As we have seen here with EB-derived neurons, others have also reported ES-derived neurons with morphologies reminiscent of cortical projection neurons, but it was interesting that only neurons differentiated from MS5-NPCs exhibited prominent synaptic spines on their dendrites that are critical hallmarks of connectivity within cortical neural networks. The observation that the EB-NPC-produced neurons did not have spines and very few subcortical projecting axons suggests that the EB-neurons are not bona fide cortical pyramidal neurons as well as strongly indicating that previous in vitro fate specification is required for neurons to become cortical pyramidal neurons.

\section{Gene expression profile of MS5-induced NPCs and neurons}

We found 5 of 34 forebrain genes that were differentially expressed in MS5-NPCs when compared with EB-NPCs. Fez is not highly expressed in the cortex and may represent a different subpopulation of neurons (Hirata et al., 2006). Emx1, Otx1, and FoxG1 are expressed in the developing cortex and have roles in early neurogenesis (Frantz et al., 1994; Weimann et al., 1999; Bishop et al., 2003; Hanashima et al., 2007). The observation that these three genes are not expressed in EB-NPCs supports our contention that the embryoid body/RA neural induction method does not produce cortical pyramidal neurons. Notably, Fezf2 is expressed in subcortical projection neurons and null mice show disrupted subcortical axon projections and completely fail to project axons to the spinal cord (Chen et al., 2005; Molyneaux et al., 2005).

Rather unexpectedly, we found that the gene, Ctip2, which has a very similar phenotype to Fezf2 (Arlotta et al., 2005) and is thought to act downstream of Fezf 2 during cortical development (Leone et al., 2008), was expressed in both NPC populations. However, expression of Ctip2 in the EB-NPC-induced neurons was insufficient for the establishment of subcortical axons, suggesting that other genes acting in concert are necessary. Gain/loss of function experiments in ES cells and neural induction in this system may provide insights into how these genes interact and whether other gene products are required, highlighting the utility of using ES cells to dissect pathways in developmental neurobiology.

Interestingly, the MS5-induced ES cells did not form tumors even 1 year after transplantation, in contrast to the embryoid body method in which small to large tumor were observed after only 3 months. This may reflect the more differentiated nature of the MS5-induced NPCs as evident by the lower frequency of nestin and RC2 immunoreactivity in these cells after 1 week of differentiation in vitro.

A previous report has demonstrated a method using the Sonic Hedgehog antagonist cyclopamine that neuralized ES cells toward a cortical pyramidal fate (Gaspard et al., 2008). These ESderived neurons projected axons to targets of visual cortex regardless of where in the cortex the cells were transplanted. Thus, cells transplanted into the motor cortex projected axons to visual subcortical targets and never to the spinal cord. One explanation for this observation is that the neuralizing method used in this report specified all of the neurons toward a visual cortex fate and the differentiating neurons behaved as if they were visual cortical neurons regardless of site of transplantation. Alternatively, this method may have specified many features of cortical neurons but not the crucial phenotype of correct and arealspecific axonal projection.

\section{Implication for clinical studies}

Establishing appropriate connectivity of transplanted neurons will constitute an essential element of any successful neuronal replacement strategy. Previous studies have demonstrated that it is possible to establish such connections with tissue grafts but accomplishing this on a large scale with dissociated cells (which represents a more clinically feasible approach) has not been previously documented. Therefore, the demonstration that this effect occurs after preconditioning ES cells (which theoretically at least can be produced in large quantities) on a stromal layer and is a result of expression of a limited subset of genes suggests that it should be possible to develop methods for additional enrichment of these cell populations.

\section{References}

Arlotta P, Molyneaux BJ, Chen J, Inoue J, Kominami R, Macklis JD (2005) Neuronal subtype-specific genes that control corticospinal motor neuron development in vivo. Neuron 45:207-221.

Bain G, Kitchens D, Yao M, Huettner JE, Gottlieb DI (1995) Embryonic stem cells express neuronal properties in vitro. Dev Biol 168:342-357.

Barberi T, Klivenyi P, Calingasan NY, Lee H, Kawamata H, Loonam K, Perrier AL, Bruses J, Rubio ME, Topf N, Tabar V, Harrison NL, Beal MF, Moore MA, Studer L (2003) Neural subtype specification of fertilization and nuclear transfer embryonic stem cells and application in parkinsonian mice. Nat Biotechnol 21:1200-1207.

Beddington RS, Robertson EJ (1998) Anterior patterning in mouse. Trends Genet 14:277-284.

Bibel M, Richter J, Schrenk K, Tucker KL, Staiger V, Korte M, Goetz M, Barde YA (2004) Differentiation of mouse embryonic stem cells into a defined neuronal lineage. Nat Neurosci 7:1003-1009.

Bishop KM, Garel S, Nakagawa Y, Rubenstein JL, O'Leary DD (2003) Emx1 and Emx2 cooperate to regulate cortical size, lamination, neuronal differentiation, development of cortical efferents, and thalamocortical pathfinding. J Comp Neurol 457:345-360.

Boillée S, Vande Velde C, Cleveland DW (2006) ALS: a disease of motor neurons and their nonneuronal neighbors. Neuron 52:39-59.

Brüstle O, Spiro AC, Karram K, Choudhary K, Okabe S, McKay RD (1997) In vitro-generated neural precursors participate in mammalian brain development. Proc Natl Acad Sci USA 94:14809-14814.

Chen B, Schaevitz LR, McConnell SK (2005) Fezl regulates the differentiation and axon targeting of layer 5 subcortical projection neurons in cerebral cortex. Proc Natl Acad Sci U S A 102:17184-17189.

Connors BW, Gutnick MJ (1990) Intrinsic firing patterns of diverse neocortical neurons. Trends Neurosci 13:99-104.

Dräger UC, Hubel DH (1976) Topography of visual and somatosensory projections to mouse superior colliculus. J Neurophysiol 39:91-101.

Eiraku M, Watanabe K, Matsuo-Takasaki M, Kawada M, Yonemura S, Matsumura M, Wataya T, Nishiyama A, Muguruma K, Sasai Y (2008) Self-organized formation of polarized cortical tissues from ESCs and its active manipulation by extrinsic signals. Cell Stem Cell 3:519-532.

Frantz GD, Weimann JM, Levin ME, McConnell SK (1994) Otx1 and Otx2 
define layers and regions in developing cerebral cortex and cerebellum. J Neurosci 14:5725-5740.

Friedel RH, Plump A, Lu X, Spilker K, Jolicoeur C, Wong K, Venkatesh TR, Yaron A, Hynes M, Chen B, Okada A, McConnell SK, Rayburn H, TessierLavigne M (2005) Gene targeting using a promoterless gene trap vector ("targeted trapping") is an efficient method to mutate a large fraction of genes. Proc Natl Acad Sci U S A 102:13188-13193.

Gaillard A, Prestoz L, Dumartin B, Cantereau A, Morel F, Roger M, Jaber M (2007) Reestablishment of damaged adult motor pathways by grafted embryonic cortical neurons. Nat Neurosci 10:1294-1299.

Gao WJ, Zheng ZH (2004) Target-specific differences in somatodendritic morphology of layer V pyramidal neurons in rat motor cortex. J Comp Neurol 476:174-185.

Gaspard N, Bouschet T, Hourez R, Dimidschstein J, Naeije G, van den Ameele J, Espuny-Camacho I, Herpoel A, Passante L, Schiffmann SN, Gaillard A, Vanderhaeghen P (2008) An intrinsic mechanism of corticogenesis from embryonic stem cells. Nature 455:351-357.

Hains BC, Black JA, Waxman SG (2003) Primary cortical motor neurons undergo apoptosis after axotomizing spinal cord injury. J Comp Neurol 462:328-341.

Hanashima C, Fernandes M, Hebert JM, Fishell G (2007) The role of Foxg1 and dorsal midline signaling in the generation of Cajal-Retzius subtypes. J Neurosci 27:11103-11111.

Hardy SG, Leichnetz GR (1981) Frontal cortical projections to the periaqueductal gray in the rat: a retrograde and orthograde horseradish peroxidase study. Neurosci Lett 23:13-17.

Hattox AM, Nelson SB (2007) Layer V neurons in mouse cortex projecting to different targets have distinct physiological properties. J Neurophysiol 98:3330-3340.

Hevner RF (2006) From radial glia to pyramidal-projection neuron: transcription factor cascades in cerebral cortex development. Mol Neurobiol 33:33-50.

Hirata T, Nakazawa M, Yoshihara S, Miyachi H, Kitamura K, Yoshihara Y, Hibi M (2006) Zinc-finger gene Fez in the olfactory sensory neurons regulates development of the olfactory bulb non-cell-autonomously. Development 133:1433-1443.

Koester SE, O'Leary DD (1992) Functional classes of cortical projection neurons develop dendritic distinctions by class-specific sculpting of an early common pattern. J Neurosci 12:1382-1393.

Konur S, Ghosh A (2005) Calcium signaling and the control of dendritic development. Neuron 46:401-405.

Lamba DA, Gust J, Reh TA (2009) Transplantation of human embryonic stem cell-derived photoreceptors restores some visual function in Crxdeficient mice. Cell Stem Cell 4:73-79.

Larsen DD, Callaway EM (2006) Development of layer-specific axonal arborizations in mouse primary somatosensory cortex. J Comp Neurol 494:398-414.

Leone DP, Srinivasan K, Chen B, Alcamo E, McConnell SK (2008) The determination of projection neuron identity in the developing cerebral cortex. Curr Opin Neurobiol 18:28-35.
Luo L, O'Leary DD (2005) Axon retraction and degeneration in development and disease. Annu Rev Neurosci 28:127-156.

Molyneaux BJ, Arlotta P, Hirata T, Hibi M, Macklis JD (2005) Fezl is required for the birth and specification of corticospinal motor neurons. Neuron 47:817-831.

Morizane A, Takahashi J, Shinoyama M, Ideguchi M, Takagi Y, Fukuda H, Koyanagi M, Sasai Y, Hashimoto N (2006) Generation of graftable dopaminergic neuron progenitors from mouse ES cells by a combination of coculture and neurosphere methods. J Neurosci Res 83:1015-1027.

Muotri AR, Gage FH (2006) Generation of neuronal variability and complexity. Nature 441:1087-1093.

Muotri AR, Nakashima K, Toni N, Sandler VM, Gage FH (2005) Development of functional human embryonic stem cell-derived neurons in mouse brain. Proc Natl Acad Sci U S A 102:18644-18648.

Okada A, Lansford R, Weimann JM, Fraser SE, McConnell SK (1999) Imaging cells in the developing nervous system with retrovirus expressing modified green fluorescent protein. Exp Neurol 156:394-406.

O'Leary DD, Koester SE (1993) Development of projection neuron types, axon pathways, and patterned connections of the mammalian cortex. Neuron 10:991-1006.

O'Leary DD, Borngasser DJ, Fox K, Schlaggar BL (1995) Plasticity in the development of neocortical areas. Ciba Found Symp 193:214-230; discussion 51-57.

Reep RL, Corwin JV, Hashimoto A, Watson RT (1987) Efferent connections of the rostral portion of medial agranular cortex in rats. Brain Res Bull 19:203-221.

Rozen R, Skaletsky HJ (2000) Primer3 on the WWW for general users and for biologist programmers. Totowa, NJ: Humana.

Stern CD (2005) Neural induction: old problem, new findings, yet more questions. Development 132:2007-2021.

Suzuki M, Svendsen CN (2008) Combining growth factor and stem cell therapy for amyotrophic lateral sclerosis. Trends Neurosci 31:192-198.

Svendsen CN, Bhattacharyya A, Tai YT (2001) Neurons from stem cells: preventing an identity crisis. Nat Rev Neurosci 2:831-834.

Tropepe V, Hitoshi S, Sirard C, Mak TW, Rossant J, van der Kooy D (2001) Direct neural fate specification from embryonic stem cells: a primitive mammalian neural stem cell stage acquired through a default mechanism. Neuron 30:65-78.

Tseng GF, Prince DA (1993) Heterogeneity of rat corticospinal neurons. J Comp Neurol 335:92-108.

Weimann JM, Zhang YA, Levin ME, Devine WP, Brûlet P, McConnell SK (1999) Cortical neurons require Otx1 for the refinement of exuberant axonal projections to subcortical targets. Neuron 24:819-831.

Wernig M, Benninger F, Schmandt T, Rade M, Tucker KL, Büssow H, Beck H, Brüstle O (2004) Functional integration of embryonic stem cell-derived neurons in vivo. J Neurosci 24:5258-5268.

Wichterle H, Lieberam I, Porter JA, Jessell TM (2002) Directed differentiation of embryonic stem cells into motor neurons. Cell 110:385-397. 